\title{
Compositional content of English musical and rock opera texts: linguistic aspect
}

\author{
Venera Alpysbayeva - Togzhan Ospanova - Beishenaliev Almazbek - Tony \\ Dimitrova Shekerdzhieva-Novak - Begalinova Gulnar
}

DOI: 10.18355/XL.2021.14.02.04

\begin{abstract}
Every day, every active member of society deals with various types of media, interacts with other people, is engaged in cognitive activities while falling under the influence of external factors that influence a person's consciousness, thinking, and behavior. All these processes take place in a communication situation, in which the individual inevitably becomes a participant when interacting with the outside world. One of the goals of research in the field of communicative linguistics is to identify and formulate criteria for ensuring the success (consistency) of speech interaction. Our research is devoted to the study of the linguistic problem of the text, which is proposed to be considered on the example of a musical and rock opera text as an element of a particular communicative phenomenon - musical and poetic discourse. The relevance of the work is based on the importance of the role of the linguistic component in the process of creating and perceiving the lyrics of a number of modern musical styles, which are currently one of the actively used tools for conveying information to the mass audience and influencing both the communicative activity of an everyday person and his worldview. The scientific novelty of this research lies in the fact that for the first time, it analyzes a previously unexplored linguistic phenomenon - the linguistic, musical, and rock opera texts. The uniqueness of the study lies in the fact that the theoretical and practical aspects of the functioning of texts are analyzed, the previously existing interpretations of this concept are systematically considered and based on our interpretation of this term, for the first time, an analysis is carried out concerning the corresponding type of discourse.
\end{abstract}

Key words: characteristics, professional language, linguistics, rock opera texts, English musicals

\section{Introduction}

The second half of the 20th century went down in the history of linguistics as a period of active emergence of new directions and approaches to the study of language and the formation of several new linguistic disciplines. One example of this is the linguistics of the text, which emerged as a separate discipline with its own ontological status in the second half of the century during the heyday of formal grammars. The programmatic thought for this area of linguistics was the idea of M.M. Bakhtin that the text is the primary given of all human and philosophical thinking (Turaeva, 1986). "The text is that immediate reality (the reality of thought and experience), from which alone these disciplines and this thinking can proceed. Where there is no text, there is no object for research and thinking" (Bakhtin, 1986: 297).

Modern linguistics is characterized by an increased interest in a number of problems associated with the ideas of linguistic pragmatics, the theory of speech acts, and cognitive science. At the same time, the study of the functional stratification of language in its connection with human activity in all the various aspects of its manifestation also remains in the focus of attention of modern linguistics. The growing role of science in modern society has required linguistics to carefully consider the scientific text as a means of communication and as a way of fixing scientific knowledge. Even though in recent years in the study of issues related to the specifics and patterns of scientific speech, significant progress has been achieved, 
there are problems that have not yet received their full coverage or have not been sufficiently studied. This, in particular, applies to the study of imagery in a musical and rock text.

An uncountable number of works and studies have been devoted to the study of the text, yet there is still no generally accepted definition of the text. Analyzing the definitions of the text proposed by various scholars, L.G. Babenko and Yu.V. Kazarin note that two of their main varieties can be distinguished: laconic, figurative formulations, and detailed definitions of a complex nature, designed to give a volumetric characterization of the text with a set of its most important features (Babenko, Kazarin, 2005). Considering the formulations given by the authors as examples, one can conclude that each definition is built around one or more dominant properties of the text. Thus, the text is considered as "the manifestation of the laws of reality" ( Myshkina), and "the linguistic expression of the creator's intention" (Likhachev). The importance of the text for the communicative process is indicated by L.V. Sakharnyi, emphasizing functional completeness of the text as a speech.

There is a wide and narrow understanding of the term 'text.' With any understanding of this term, a text is understood as a sequence of sign units united by a semantic connection, the main properties of which are coherence, integrity, completeness. In addition, according to A. Vasilieva, the text as "an independent holistic, purposeful complex speech structure" has a number of features, namely: independence, purposefulness, single-subjectness, limited time and space (Vasilieva, 1990). Bringing the concepts of text and style closer together, P. Guiraud believes that "a text is a structure, a closed organized whole, within which signs form a system of relations that determine the stylistic effects of these signs" (Guiraud, 1980).

The text can be structured from the point of view of psycholinguistics, sociolinguistics, as well as computational linguistics, and other branches of science, which consider various aspects of the text as a linguistic unit. However, the linguistics of the text at the present time is most likely aimed at describing such a structure of the text, which could be universal for all types of texts with different contents, compositions, and functional features. Along with this, in the global structure of the text, each text is characterized by unique, specific structural features. The order of supraphrasal units, sentences, words and phrases, and even prosodic features in each text appear in a peculiar and unique way, which manifests the typological features of texts both in languages considered separately or comparatively. The complexity of determining the structure of the text lies in the organizational features of this linguistic addition.

In modern literature, the concept of "text" is considered in the context of its broad and narrow understanding. According to V.B. Kasevich, "text in a broad sense - this is the same as speech, a product of production, speaking (for sound language). A text in the narrow sense is a unit of speech (i.e., a text in a broad sense), which is characterized by integrity and internal coherence and as such can be isolated, delimited from the previous and subsequent texts" (Kasevich, 1985).

A musical and rock opera text is a complex phenomenon of cultural activity, which is investigated and analyzed in many aspects. The process of adapting a literary text to study it can take various forms according to certain goals and objectives of transformation. In the process of adapting a literary text, similar trends are revealed: on the one hand, preserving the content structure of the original text through synonyms, lexical changes based on active reader's dictionary; on the other hand, the preservation of the structure of the original artistic text in spite of grammatical, word-order, or compositional changes; analog - the process of translation: "the equivalence of the original and the translation is based, first of all, on the identity of semantic information" (A. Barkhudarov, 1974); and also - preservation of the stylistic coloring of the original text with a possible change in the emotional-evaluative

XLinguae, Volume 14 Issue 2, April 2021, ISSN 1337-8384, eISSN 2453-711X 
component due to the exclusion of particles and a change in the subjective word order to the objective one.

Musical and rock opera text is one of the earliest forms of expressing artistic thought. Romantic philosophers and scientists have sought the origins of language in the emotional and poetic impulses of a person (Arutyunova,1990). Features of poetry, poetic language, and speech attract the attention of scientists from various fields of knowledge - philologists, philosophers, linguists, mathematicians, while the areas of research affect an increasing number of characteristics of the poetic text. The analysis of phonetic features of musical and rock opera technique is examined, features of musical and rock opera syntax is carried out, and the theory of verification is investigated. Also conducted is the study of cultural aspects of such texts, their discursive space, etc.

Interactive human activity, taking place in a wide socio-cultural context and bearing a musical and rock opera character, form a musical and rock opera discourse. Within the framework of this study, we will adhere to the definition of I.I. Chumak-Jun, according to which musical and rock opera discourse is "a complex, nonlinearly organized system of musical and rock opera texts, the figurative and speech elements of which are an integrative and systemically connected unity of their linguistic, pragmatic, socio-cultural, mental and paralinguistic properties. Understanding musical and rock opera discourse as a system includes both the dynamic process of figurative speech activity, inscribed in the corresponding metacontext, and its result - a musical and rock opera text" (Chumak-Zhun, 2009).

The purpose of the study is to analyze the compositional content of English musical and rock opera texts, taking into account the leading principles of the modern linguistic aspect.

To achieve this, it is necessary to study and summarize various approaches to analyzing text composition, developing a methodology for analyzing the composition, and identifying elements at different levels of the text.

The result of musical and rock opera discourse, its communicative event is a text. Arguing about the linguistic definition of a musical and rock opera text, Yu.V. Kazarin (Kazarin, 1999) notes that a musical and rock opera text is a multifaceted phenomenon. Such a text can be considered only taking into account its intra-text and extra-text sides, as well as factors that determine its specificity as a number of entities (categories), the most important of which are for the study of linguistic. The author considers the following sides of the question:

- a linguistic category, which has its own plan of expression and content, the specificity of which is determined by the units of a sign system that has a sign nature and a level hierarchical structure;

- an anthropolinguistic category, which contains an individual author's artistic picture of the world, as well as containing linguistic signs and features of individual (author's, subjective) poetic thinking (poetic nomination in the first place) and generalized (objective, invariant) linguistic thinking;

- a cultural category, that is, the symbolic systematicity of a musical and rock opera text is related to the symbolic system (symbolic systems, symbolism in general) of culture (Murzin, 1994);

- an aesthetic category, since a specific poetic text is always created in one or another aesthetic framework of a method, school, direction, i.e., is objectively a part of the whole aesthetics of fine literature (the aesthetics of verbal creativity) (Bakhtin, 1979); - a spiritual category as the highest manifestation of cultural (intellectual, emotional, psychological, humanitarian, etc.) human activity along with other kinds and types of art, science, technology, and philosophy.

In modern linguistic and philosophical traditions, the musical and rock opera text is defined as a system of sign nature, which is an integral part of culture; it is a process and result of artistic thinking, based on a particular type of musical and rock opera 
nomination, or renomination. It has its own textual qualities that modify the poetic text as a special version of the literary text.

Understanding the text in linguistics is united by the postulate that the text has a certain semantic significance, that is, it carries information that, at the request of the sender, must be conveyed to the addressee. So, V.P. Rudnev understands a musical and rock opera text as a kind of artistic text, which is reduced to a text in a broad sense as a signal embodied in objects of physical reality, transmitting information from one consciousness to another and therefore does not exist outside the consciousness that perceives it (Rudnev, 2000). In accordance with the interpretation of M.G. Aranovsky, a musical and rock opera text is such a sound sequence that is interpreted by the subject as relating to music. It is a structure built according to the norms of any historical variety of musical language and carries one or another intuitively comprehended meaning (Aranovsky, 1998). According to M.M. Bakhtin, a musical and rock opera text is a specific sign structure, the purpose of which is to convey artistic information of sound-temporal properties by the composer to the listener (Bakhtin, 1986).

\section{Discussion}

Within the framework of this research, it is proposed to consider the features of the linguistic of a musical and rock opera text using the example of the texts of thirty-five English songs in the "rock" and "metal" style of fifteen musical groups. The total number of tokens of the considered volume of the text is about 5000 units. Bookletsattachments to the corresponding musical recordings were used as sources of material. The sample was made while taking into account a number of restrictions. Thus, the material did not include texts compiled in violation of the norm of the literary language, containing an excessive number of slang units. The songs, the texts of which are being analyzed, are examples of the most popular and highly appreciated works of the given group, which allows us to conclude that they have successfully performed function.

When creating a musical and rock text, lexical units are not selected only for the main but also for minor signs, for the secondary semantic coloring. "These are the secondary signs of words inside the stitch series, cumulating, they can form such a 'rich context' that it becomes possible to skip any essential for the main semantic features of a word within a scribble (a phenomenon that is impossible or extremely rare in ordinary speech)" (Leontiev, 2005).

Special lexical and semantic units, contributing to the formation of a text as an object with an increased aesthetic load, also contribute to the formation of an artistic image reflected in the art piece.

Among the lexical and semantic markers found in the texts under consideration, the following are most common:

Metaphor: "give me wings to fly, ride the sky" ("Ride The Sky," Helloween); "touching the stars " ("Clown In The Mirror," Royal Hunt); "oceans of pain," "ounce of pain" ("Sweet Child O'Mine," Guns N' Roses), "we take away tomorrow," "if you cross the gates of wisdom" ("Guardians of The Flame," Virgin Steele), "ride the winds of the sky" ("Perfect Mansions," Virgin Steele).

Metonimy: "there's a big black shape looking up at me" ("Heaven And Hell," DIO); "there's a thousand eyes upon you" ("Guardians of The Flame," Virgin Steele);

Simily: "your face just like an angel, smiling up at me" ("Cry Forever," Virgin Steel); "where everything was as fresh as the bright blue sky," "eyes of the bluest skies, as if they thought of rain" ("Sweet Child O'Mine," Guns N' Roses); "shiny diamonds like the eyes of the cats in the black and blue," "life's a never ending wheel" ("Holy Diver," DIO); "life is like a carousel" ("Heaven And Hell," DIO).

XLinguae, Volume 14 Issue 2, April 2021, ISSN 1337-8384, eISSN 2453-711X 
Antithesa: "lived in the crowd but dying all alone," "glitter and scars" ("Clown In The Mirror," Royal Hunt); "it goes on and on and on - it's heaven and hell," "they'll tell you black is really white, the moon is just the sun at night" ("Heaven And Hell," DIO); "born to cany the flame, bringing light to the dark" ("Maybe I, Maybe You," The Scorpions);

Epithet as the tool of expression: "sweet dreams," "perfect mansions," "silver horses," "forbidden forests by the shore," "brave men," "endless knowledge," "endless time," "wild fantasy."

Also, during analyses, we faced expressiveness on the syntax level. The syntactic structure of musical accompaniment can be called upon to emphasize semantically and stylistically significant words. So, in the line of the song "Gates of Valhalla" ("Manowar") "Raise high your hands to bid a last farewell to the Viking land," the pause between the words "last" and "farewell," due to the peculiarities of the structure of the musical arrangement of the verse, gives a special the semantic load of the idea of "last goodbye," which, in addition, is already presented quite vividly lexically due to the combination of the concept of "farewell" with the concept of "last" which is self-evident from a semantic point of view. In general, the arrangement of pauses within the syntagma, due to the peculiarities of musical syntax, is one of the most popular techniques for highlighting semantically significant components, to some extent being an auditory analog of the parceling technique.

One of the most frequently used methods of constructing syntactic constructions is the lexical, syntactic, and stanza-syntactic anaphora, which consists of repeating similar syntactic constructions at the beginning of each row.

One of the most common methods of constructing musical and poetic texts to make them easier to remember is the repetition of complex syntactic elements, such as syntagmas, as a rule, occurring in the chorus due to the specifics of this component compositional structure of the song. Frequently repeated sections of text include the title of the work or completely coincide with it, thus fixing the reference connection between the song as a sign or sign system and its semantic content.

From a semantic point of view, a musical poetic text is a synthesis of the features of the semantic content of music and the transmission of content using natural language. Despite a number of qualitative differences between music and verbal language phenomena, both of these phenomena also have many common characteristics that provide the logical and physical possibility of their harmonious integration into a single whole.

The material for the research was the texts of English-language songs in the style of "rock" and "metal" musical groups. When sampling texts, the factor of popularity of a particular song was taken into account both among fans of the genre and among representatives of the audience who are not directly related to it. The popularity of a song as a complex object allows us to state that it successfully fulfills its attractive function. We set ourselves the goal of identifying the linguistic features of a musical text as a special communicative phenomenon.

\section{Conclusion}

The musical text is a complex sign system that meets the basic general requirements for constructing a text, which is the result of artistic thinking, implying the presence of a poetic component presented in combination with an individual musical accompaniment that determines the unique features of its form and content. Within the traditional communicative situation framework, musical discourse is a kind of oral discourse, which distinguishes it from other types of discourse.

In the process of perception, a person's ability to simultaneous perception, that is, the perception of complex objects as integral and indivisible, is confirmed. Researching the behavior of text material under the influence of deliberately selected musical accompaniment will allow to formulate the features inherent in the phenomenon of 
attraction in the framework of the object under consideration and identify common systemic regularities of the functioning of the linguistic parameter. The structure of the analyzed material at different levels of language perception, the features of the communicative situation, and accompanying extralinguistic factors should be taken into account.

The significance of the study is that it contributes to the identification of structural features and perception of structures within the framework of a musical and rock opera text as a particular communicative phenomenon. The features of the modern approach to the perception and understanding of the musical and rock opera text as a complex polycode structure are analyzed. The work is also significant in studying the trends in the development and functioning of musical discourse in the late $20^{\text {th }}$ and early $21^{\text {st }}$ centuries.

The practical value of the work lies in the possibility of using the research results in the development of courses of lectures and seminars on general linguistics, text linguistics, discourse analysis, communicative linguistics, psycholinguistics, sociolinguistics, special courses on the problems of artistic communication in general and musical and poetic communication as its component. In addition, the results presented in this study can be useful when conducting research in related fields of knowledge, such as cultural studies, psychology, and sociology. The provisions and conclusions contained in the research can be used to further study the issues of the structure, perception, and functioning of the structures of texts, as well as the features of musical and rock opera text presented in various forms, as one of the means of providing speech impact on the audience. Our findings can find application in the compilation of textbooks on discourse, in the writing of term papers (especially for students at language faculties of universities). The factual material can be used to solve several applied problems, in particular, to effectively achieve certain communication goals using texts, including both verbal and musical components.

\section{Bibliographic references}

ARUTYUNOVA, N.D. 1990, Metaphor and discourse. Metaphor theory. In: Progress, pp. 5-32. ISBN 5-01-001599-4

BABENKO, L.G. - KAZARIN, Yu.V. Linguistic analysis of literary text. M: Flinta: Nauka, 2005.496 p. ISBN 5-89349-337-0

BAKHTIN, M.M. The problem of the text in linguistics, philology and other humanities Text. Aesthetics of verbal creativity. Art, 1986.p. 297-325. УДК: 378:81

GALPERIN, I.R. Text as an object of linguistic research Text. / I.R. Halperin. Ed. 6th. Moscow: LKI Publishing House, 2008. УДК 81'271

ESPERSEN, O. Philosophy of Grammar Text. O. Espersen. Moscow: Inlitizdat, 1958. Д 212.29605

BENVENISTE, E. General Linguistics Text. E. Benveniste; ed., with enter, article and comment. ISBN 5-7859-0027-0..

GUILLAUME, G. Principles of Theoretical Linguistics Text. G. Guillaume: Sat. unedited texts; prepare under the hands. R. Valen; translation from fr. P.A. Skrelin; total ed., after. and comments. L.M. Skrelin. M .: Progress. Culture, 1992. ISBN 5354-00684-8

KUBRYAKOVA, E.S. Paradigms of scientific knowledge in linguistics and its1 modern status Text. E.S. Kubryakova Izvestia, RAS: SLYa. 1994. -T.53. -No 2.p. 315. ISBN 978-5-248-00436-2

ILYENKO, S.G. Three aspects of compositional and stylistic analysis of a literary text as a holistic formation Text. S.G. Ilyenko Ilyenko S.G. Russistics: Selected Works. $\mathrm{SPb}$.: RGPU im. A.I. Herzina, 2003 .-- p. 495-509. ISBN 978-985-536-114-6. 
ODINTSOV, V.V. Stylistics of the text Text. V.V. Odintsov. M .: Publishing house "Science", 1980. ISBN 5-8297-0146-4

Buhler, K. Theory of language Text. K. Buhler. M .: Progress - Univers, 1993. ISBN 9789027211828

VINOGRADOV, V.V. About the language of fiction Text. / V.V. Vinogradov. -M .: GIHL, 1959. ISBN 978-5-389-04580-4

KAIDA, L.G. Compositional Analysis of Literary Text: Theory. Methodology. Feedback algorithms Text. L.G. Kaida.I M .: Flinta: Nauka, 2000. ISBN 978-5-97651741-7

KARAULOV, YU.N. Russian language and linguistic personality Text. Yu.N. Karaulov. Moscow: Nauka, 1987. ISBN 978-5-382-01071-7

KOVTUNOVA, I.I. Questions of the structure of the text in the works of Acad. V.V. Vinogradova Text. I.I. Kovtunova Russian language. Text as a whole and text components: Vinogradov readings XI Otv. ed. N.Yu. Shvedova. M .: Publishing house "Science", 1982. - p. 3-18. ISBN 978-5-907032-68-2

Kovtunova, I.I. Essays on the language of Russian poets Text. I.I. Kovtunov. -M .: “Azbukovnik", 2003. . ISBN 978-5-906582-68-2

KRASNYKH, V.V. From the concept to the text and back (to the question of the psycholinguistics of the text) In: Text. V.V. Red. Vestnik Mosk. un-that. Ser. 9. Philology. 2008. - No. 1. - p. 53-70. УДК 81'27(09)

HARTUNG, Y. - BRAIDO, E. Problems of the linguistic description of the I hypertext Text. In: Y. Hartung, E. Breido. Vestnik Mosk. un-that. Ser. 9. Philology. 1996. - No. 3. The human factor in the language: Communication. Modality. pp. 6177. ISBN 5-02-011120-1

SHULEEKKOVA, S.G. History of linguistic studies. In: Text, Textbook for students of philological faculties. S.G. Shulezhkova. Moscow, Flinta: Nauka, 2004. ISBN 594457-016-4

SHCHERBA, JI.B. From the linguistic heritage. In: L.V. Shcherba: Questions of linguistics. 1962. Vol. 2. pp. 96-101. УДК 81'367; 81'367.4

SHCHEULIN, V.V. - POPOVA, E.A. Anthropocentrism at the present stage of linguistics Text. In: V.V. Shcheulin, E.A. Popova: Anthropocentrism of the modern linguistic situation. ed. E.A. Popov. Lipetsk, 2002 . pp. 3-27. ISBN 978-5-98269-1408.

LANGUAGE AND COMPOSITION OF LITERARY TEXT (RUSSIAN) TEXT .: Interuniversity collection of scientific papers. Otv. ed. L.Yu. Maximov. M., 1986. Д 212.109.01

JACOBSON, P.O. Linguistics and poetics Text. In: Structuralism: "for" and "against" Ed. E. Ya. Basin and M. Ya. Polyakova. Moscow: Progress, 1975. pp. 193-230. ISBN 978-5-7139-1361-8

VASILYEVA, S.G. Modern Russian language. Lexicology and phraseology: Textbook for universities in the specialty "Philology". - Kazan: RIC "School", 2005. P. 133. ISBN 978-5-7477-3853-9

CHUMAK-ZHUN, I.I. Discursive space of a poetic text: a figurative word in Russian lyric poetry of the late 18 th - early 21 st centuries: author. Belgorod: Belgor. state un-t, 2009.38 р. Д 21201503

Words: 4194

Characters:27 235 (15,13 standard pages) 
Venera Alpysbayeva

Phd student

Zhurgenov Kazakh National Academy of Arts,

Panfilov street, 127,

050000 Almaty

Republic of Kazakhstan

Prof. Togzhan Ospanova

Kazakh National Conservatory named after Kurmangazy,

Abylai Khan Avenue 90,

050000 Almaty

Republic of Kazakhstan

prof. dr. Almazbek Beishenaliev

Candidate of pedagogical sciences,

Kyrgyz State university named after I. Arabayev,

st. Razzakov, 51A,

720026, Bishkek

Kyrgyzstan

Tony Dimitrova Shekerdzhieva - Novak

Phd, Faculty of Musical Education,

Department of Orchestra Instruments and Classic Singing,

Academy of Music, Dance and Fine Arts,

st. "Todor Samodumov" 2,

4000 Staria grad, Plovdiv,

Bulgaria

Gulnar Begalinova

Zhurgenov Kazakh National Academy of Arts

Panfilov street, 127,

050000 Almaty

Republic of Kazakhstan

lunaranurbek@gmail.ru 